\title{
Effect of Neem Leaves Extract (Azadirachta Indica) on Wound Healing
}

\author{
Naveen Kumar Chundran, ${ }^{1}$ Ike Rostikawati Husen, ${ }^{2}$ IrraRubianti ${ }^{3}$ \\ ${ }^{1}$ Faculty of Medicine Universitas Padjadjaran, ${ }^{2}$ Department of Pharmacology and Therapy \\ Faculty of Medicine Universitas Padjadjaran, ${ }^{3}$ Department of Plastic Surgery Faculty of Medicine \\ Universitas Padjadjaran/Dr. Hasan Sadikin General Hospital Bandung
}

\begin{abstract}
Background: Neem leaves (Azadirachta Indica) have active ingredients such as nimbidin and sodium nimbidate which possess/possesinganti-inflammatory, antibacterial, antifungal and antiviral properties that help in healing process and also contains an excellent nutrition which plays/playing a vital role in formation of collagen and formation of new capillaries. The aim of this experimental study is to evaluate healing activity of neem leaves.

Methods: This experiment was conducted in Pharmacology Lab of Universitas Padjadjaran on October 2012. Twenty seven rats were grouped randomly into 3 groups and $1.5 \mathrm{~cm}$ of excision wound was created. Negative control group was treated with a topical application of saline solution (sodium chloride $0.9 \%$ ), treatment group with a topical application of neem leaves extract and positive control group had been treated with a topical application of povidone-iodine for 15 days. Healing was assessed by the longest diameter of the raw surface of wound on days 0,5,10 and 15. The data were then analyzed using Mann-Whitney U test.

Results: There was a significant reduction in the longest diameter of wound in group of neem leaves extract, compared with group sodium chloride $0.9 \%$,.and there was no significant difference in the longest diameter of wound between neem leaves, extract and povidone iodine.

Conclusions: Neem leaves extract has the same wound healing rate compared to povidone iodine. A further study in human should be conducted in the future. [AMJ.2015;2(1):199-203]

Keywords: Neem, povidone iodine, wound healing
\end{abstract}

\section{Introduction}

The skin, as the body's largest organ consists of two layers, epidermis and dermis. ${ }^{1}$ Human skin provides protection for the body from external environment, preventing dehydration, regulates body temperature, detects cutaneous sensation, and synthesizes vitamin D. ${ }^{2}$ The skin barrier can be broken, such as from a wound. ${ }^{3}$ There are many types of wound which have been classified into two major groups, open and closed wound. ${ }^{4}$

Healing is a process to replace damaged tissue, organs, and biological system to normal function. Injury will initiate a series of event to repair the damaged skin and reform its normal structure. There are four phases in wound healing process, haemostasis, inflammation, proliferation, and remodeling. ${ }^{5-8}$

Neem (Azadirachta Indica) is a well known medicinal plants, having a wide spectrum of biological activity as a traditional medicine for household remedy against various human ailments in ayurveda and homoeopathic medicine. Recent studies and research show that neem contains many therapeutic effects such as anti-inflammatory, anti-diabetic, antifungal, antiviral, antibacterial, and anti-malarial. Neem contains many active ingredients such as nimbidin, nimbin, and nimbidol with anti-inflammatory, antibacterial, antifungal and antiviral properties that may help it accelerating the wound healing process. In addition, neem contains an excellent amount of amino acid, vitamin and mineral that is very important in wound healing processes in proliferation phase. ${ }^{9}$ So, there is a possible effect that neem can accelerate the process. The aim of this study is to find out whether neem leaf extract can accelerate the duration of wound healing.

Correspondence: Naveen Kumar Chundran, Faculty of Medicine, Universitas Padjadjaran, Jalan Raya BandungSumedang Km.21, Jatinangor, Sumedang, Indonesia, Phone: +6287827969020 Email: naveen_160888@yahoo.com 


\section{Methods}

An experimental study was conducted using 27 rats (Rattus norvegicus) strain wistar. These rats were all male, aged between 2-3 months and weighing about 200-250 grams. The rats were divided randomly into 3 groups. Each group contained 9 rats and was given intervention as followed: group 1 acted as the negative control group with a topical application of saline solution (sodium chloride $0.9 \%$ ), group 2 was the treatment group with a topical application of neem leaves extract, group 3 acted as the positive control group with a topical application of povidone-iodine solution

During the experiment period, rats were given foods and water ad libitum (free access to foods or water thereby allowing animals to self-regulate according to its biological needs). The neem leaves extract was made by using $1 \mathrm{~kg}$ of neem leaves (AzadirachtaIndica). The leaves were washed with water and air-dried at room temperature. The leaves then were powdered by mixer, macerated in 10 liter of ethanol $96 \%$ and then kept for 72 hours away from lights and high temperature. It was filtered, evaporated, and dried with Rotary evaporator.

Rats were anesthetized before and during the creation of the wounds, with $1 \mathrm{~mL}$ of intravenous ketamine. The hairs around the area of dorsal midline region were shaved clean using a shaver. Then, $1.5 \mathrm{~cm}$ diameter was measured and marks were made on the rat. Using a permanent marker, the marks of the diameter were all joined to make a circle. Using a scalpel, excision was made all around the marked circle. Then, using an anatomical pin set and a curved hemostat scissors, a full thickness of excision wound for $2 \mathrm{~mm}$ depth was created following the marked circle. Wound was left uncovered throughout the experiment. Then, apply either saline solution, neem leaves extract or the povidone-iodine solution topically according to the group the rats were placed. The intervention applied sufficiently until it covered all wound area. The wound was left uncovered and cleaned using water with gauze and applied with daily intervention. ${ }^{10}$

The longest diameter of the raw surface wound was calculated on days $0,5,10,15$ and the mean diameter of the raw surface of wound (red colour area) was compared to a control group at each time intervals. Raw surface of the wound can be differentiated from epithelisation surface by the colour, wet look and shininess.

Epithelisation surface would be pink in colour with the formation of a new epidermis while raw surface would be red in colour. Other than that, raw surface would be wet and shine

Table 1 Longest Diameter of the Raw Surface of Wound after Topical Administration of Sodium Chloride $0.9 \%$

\begin{tabular}{lcccc}
\hline \multirow{2}{*}{ No } & \multicolumn{4}{c}{ Longest Diameter Group 1 (Sodium Chloride) (cm) } \\
\cline { 2 - 5 } & Day 0 & Day 5 & Day 10 & Day 15 \\
\hline 1 & 1.4 & 1.1 & 1.5 & 1.2 \\
2 & 1.5 & 1.4 & 1.3 & 1.0 \\
3 & 1.6 & 1.8 & 1.9 & 1.6 \\
4 & 1.7 & 1.4 & 1.0 & 1.7 \\
5 & 1.5 & 1.7 & 1.5 & 1.2 \\
6 & 1.5 & 1.2 & 1.4 & 0.9 \\
7 & 1.5 & 1.3 & 2.0 & 1.8 \\
8 & 1.5 & 1.7 & 2.0 & 1.6 \\
9 & 1.5 & 1.1 & 1.2 & 1.2 \\
Median & 1.5 & 1.4 & 1.5 & 1.2 \\
Mean & 1.52 & 1.41 & 1.53 & 1.36 \\
Minimum & 1.4 & 1.1 & 1.0 & 0.9 \\
Maximum & 1.7 & 1.8 & 2.0 & 1.8 \\
\hline
\end{tabular}


Table 2 Longest Diameter of the Raw Surface of Wound After Topical Administration of Neem Leaf Extract

\begin{tabular}{lcccc}
\hline \multirow{2}{*}{ No } & \multicolumn{4}{c}{ Longest Diameter Group 2 (Neem Leaf Extract) $(\mathbf{c m})$} \\
\cline { 2 - 5 } & Day 0 & Day 5 & Day 10 & Day 15 \\
\hline 1 & 1.7 & 1.4 & 1.0 & 0.2 \\
2 & 1.5 & 1.5 & 1.3 & 0.1 \\
3 & 1.5 & 1.2 & 1.1 & 0.4 \\
4 & 1.5 & 1.2 & 1.1 & 0.3 \\
5 & 1.5 & 1.1 & 1.3 & 0.3 \\
6 & 1.6 & 1.3 & 1.2 & 0.4 \\
7 & 1.6 & 1.2 & 1.1 & 0.6 \\
8 & 1.7 & 1.3 & 0.8 & 0.2 \\
9 & 2.0 & 1.5 & 1.1 & 0.3 \\
Median & 1.6 & 1.3 & 1.1 & 0.3 \\
Mean & 1.62 & 1.3 & 1.11 & 0.31 \\
Minimum & 1.5 & 1.1 & 0.8 & 0.1 \\
Maximum & 2.0 & 1.5 & 1.3 & 0.6 \\
\hline
\end{tabular}

if it is exposed to lights or the sun meanwhile epithelisation surface would be dry and had a pale appearance.

The data were then analyzed between the groups using Mann-Whitney $U$ test to compared the efficacy and potential of each treatment group. This statistic test used a significance level $(\alpha)=0.05$, two-tailed test, $\mathrm{Z}$ table $=1.65$ with $95 \%$ confidence level.

This experiment was conducted in Pharmacology Lab of Universitas Padjadjaran on October 2012. The study was carried out with prior approval of the animal Ethical Committee, Faculty of Medicine,Universitas Padjadjaran.

\section{Results}

On day 0 the longest diameter on wound in group 1 was $1.52 \mathrm{~cm}$, whereas in group 2 Was $1.62 \mathrm{~cm}$ and in group 3 was $1.57 \mathrm{~cm}$. On day 5, the longest diameter on wound in group 1 was $1.41 \mathrm{~cm}$, whereas in group 2 was $1.3 \mathrm{~cm}$ and in group 3 was $1.34 \mathrm{~cm}$ (Table 1, 2, 3). On day 0 and day 5 there was no significant change in the longest diameter of wound between group sodium chloride $0.9 \%$ and group neem leaves extract ( $p>0.05$ ), where it can be seen from the $p$-value being 0.161 and 0.489 .

However, on days 10 and 15 there was a significant change in the longest diameter of wound from group sodium chloride $0.9 \%$ (1.53 and $1.36 \mathrm{~cm}$ ) and group neem leaves extract $(1.11$ and $0.31 \mathrm{~cm})$, where it can be seen from the $p$-value being 0.008 and $0.000(p<0.05)$.

On day 0 and day 5 there was no significant change in the longest diameter of wound between groups sodium chloride 0.9\% (1.53 and $1.41 \mathrm{~cm}$ ) and group povidone iodine (1.57 and $1.34 \mathrm{~cm})$, where it can be seen from the p-value being 0.546 and 0.730 (p > $0.05)$. However, on day 10 and 15 there was a significant change in the longest diameter of wound from group sodium chloride $0.9 \%$ (1.53 and $1.36 \mathrm{~cm}$ ) and group povidone iodine $(1.31$ and $0.37 \mathrm{~cm})$, where it can be seen from the $p$-value being 0.003 and $0.000(p<0.05)$.

On days $0,5,10$ and 15 there was no significant change in the longest diameter of wound between group 2 and group 3, where it can be seen from the p-value being 0.387 , $0.666,0.489$ and $0.546(p>0.05)$.

\section{Discussions}

Wound healing is a process that involves several phases. The initial vascular response involves a period of vasoconstriction and haemostasis. The first phase is inflammation. Inflammation will cause an increase in vascular permeability and resulting in migration of neutrophils and monocytes into the surrounding tissue. 
Table 3 Longest Diameter of the Raw Surface of Wound after Topical Administration of Povidone-Iodine (Betadine) Solution

\begin{tabular}{lcccc}
\hline \multirow{2}{*}{ No } & \multicolumn{4}{c}{ Longest Diameter Group 3 (Povidone Iodine) $\mathbf{( c m )}$} \\
\cline { 2 - 5 } & Day 0 & Day 5 & Day 10 & Day 15 \\
\hline 1 & 1.6 & 1.2 & 0.6 & 0.3 \\
2 & 1.6 & 1.4 & 1.3 & 0.2 \\
3 & 1.5 & 1.3 & 1.1 & 0.1 \\
4 & 1.5 & 1.2 & 0.9 & 0.4 \\
5 & 1.5 & 1.3 & 1.3 & 0.7 \\
6 & 1.5 & 1.4 & 0.8 & 0.6 \\
7 & 1.9 & 1.7 & 1.2 & 0.3 \\
8 & 1.5 & 1.4 & 0.8 & 0.3 \\
9 & 1.5 & 1.2 & 1.1 & 0.4 \\
Median & 1.5 & 1.3 & 1.1 & 0.3 \\
Mean & 1.57 & 1.34 & 1.01 & 0.37 \\
Minimum & 1.5 & 1.2 & 0.6 & 0.1 \\
Maximum & 1.9 & 1.7 & 1.3 & 0.7 \\
\hline
\end{tabular}

Infiltrating neutrophils cleanse the wounded area of foreign particles and bacteria. Second phase is the proliferative phase which occurs from 2 days to 3 weeks' time. In this phase formation of granulation tissue, contraction and epithelialization will take place. The final phase of wound healing is wound remodelling, including a reorganization of new collagen fibers, forming a more organized lattice structure that progressively continues to increase wound tensile strength. The remodelling process continues up to two years. ${ }^{5-8}$

In this study the wound contraction process did not begin before day 10 in all groups. On days 10 and 15, there was a significant change in wound healing between group 1 and 2, it was proved by the reduction of diameter of the wound in group 2. This shows that neem leaves extract has an active compound that has effects as anti-microbial, antioxidant and antiinflammatory.

This proves that neem accelerates the healing process by prevent the infection which can prolong the healing duration. The antiinflammatory effect of neem can be seen more accurately if the histological examination had been performed.

Neem is also an excellent wound healer that helps the body to rapidly create collagen fibers to close the wound. On day 10 and 15 , neem showed significant changes in the healing process by enhancing the proliferation phase. Neem contains an excellent amount of amino acid, vitamin and mineral that is very important in wound healing process in proliferation phase. Thus, neem accelerates the healing process by speeding up the proliferation phase. The result proves that neem leaves extract speeds up the proliferation phase in the entire wound healing process.

As a positive control, povidone iodine is an uniquely effective antiseptic and used widely for the prevention and treatment of infection. The prolonged non selective antimicrobial action of povidone iodine is unparalleled for the surface microbiocidal activity and particularly effective in treating mixed infection. Povidone iodine is suitable for hand disinfection, surgical hand disinfection, as well as preoperative and pre-puncture skin disinfection. ${ }^{11,12}$ The result proves that povidone iodine indeed increases the rate of wound healing by being a disinfectant to the wound.

Neem leaves extract and povidone iodine, both accelerate the rate of wound healing. The results shows that neem leaves extracts have the same wound healing rate compared to povidone iodine. Thus, neem leaves extract can be considered to be made an alternative choice to povidone iodine because both groups give the same outcome.

This study has limitation, histological examination of the wound was not examinated to see the inflamantory effect of neem. 


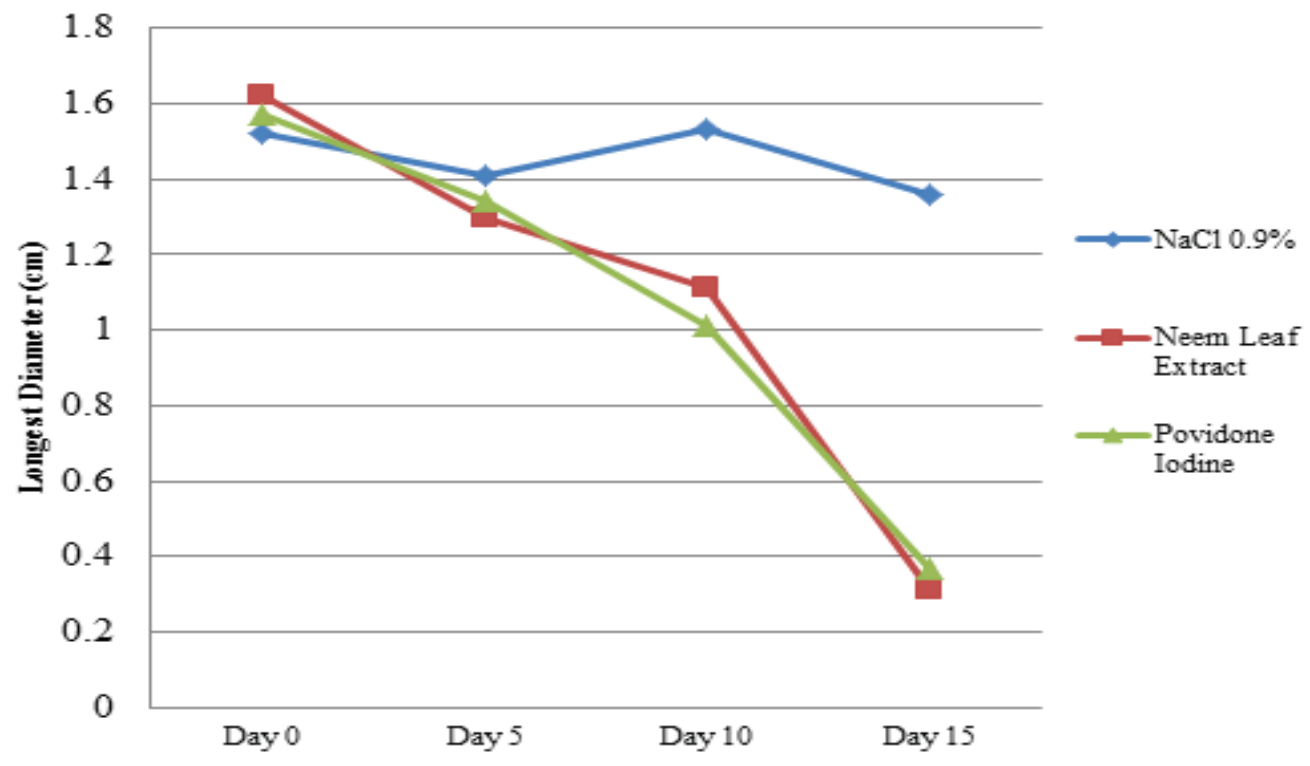

Figure 1 Mean of the Longest Diameter of The Wound in Three Groups on Day 0, 5, 10, and day 15

\section{References}

1. Mescher AL. Junqueira's basic histology: text \& atlas. 12th ed; New York:McGraw Hill Companies;2010. p. 316า-29

2. Tortora GJ, Derrickson B. Principles of anatomy and physiology. 12th ed. Hoboken:John Wiley \&Sons; 2008. p. 14774

3. Torpy JM, Burke A, Glass RM. Wound infections. JAMA. 2005; 294(16):2122.

4. Chandler S. Five types of wounds. 2011. [cited 2012 November 3]. Available from: http://www.livestrong.com/ article/101274-five-types-wounds/

5. Singer AJ, Clark RA. Cutaneous wound healing. N Eng J Med. 1999;34(10):738-46.

6. Hees CT. Understanding the barriers to healing. Adv Skin Wound Care. 2012;25(5):240

7. Diegelmann RF, Evans MC. Wound healing: an overview of acute, fibrotic and delayed healing. Front Biosci. 2004;9:283-9.

8. MacKay D, Miller AL. Nutritional support for wound healing. Altern Med Rev. 2003;8(4):359-77

9. Subapriya R, Nagini S. Medicinal properties of neem leaves: a review. Curr Med Chem Anticancer Agents. 2005;5(2):149-6.

10. Nayak BS, Sandiford S, Maxwell A. Evaluation of the wound-healing activity of ethanolic extract of morinda citrifolia L. Leaf. Evid Based Complement Alternat Med. 2009;6(3):351-6.

11. Kumar JK, Jayachandran E, Reddy HK, Gunashakaran V, Ramesh Y, Babu KP, et al. Application of broad spectrum antiseptic povidone iodine as powerful action: a review. Journal of Pharmaceutical Science and Technology. 2009;1(2):48-58.

12. Khan MN, Naqvi AH. Antiseptics, iodine, povidone iodine and traumatic wound cleansing. J Tissue Viability. 2005;16(4):610. 